\title{
Medicinas da floresta: conexões e conflitos cosmo-ontológicos
}

\section{Medicines of the forest: cosmo-ontological conflicts and connections}

Guilherme Pinho Meneses*

*Universidade de São Paulo - São Paulo, SP, Brasil

Doutorando em Antropologia Social (bolsista Capes)

guilherme.meneses@usp.br 


\title{
Resumo
}

Neste trabalho proponho descrever aspectos de um recente movimento em torno das chamadas "medicinas da floresta", principalmente o nixi pae (ayahuasca) dos Huni Kuĩ (Kaxinawá). A proposta inclui o acompanhamento de trânsitos contínuos entre a "floresta" e a "cidade" do próprio nixi pae, dos chamados pajés e de grupos ayahuasqueiros emergentes, evidenciando conexões e conflitos ontológicos. Uma contribuição possível deste trabalho é alimentar reflexões no campo ayahuasqueiro a partir de uma proposição cosmopolítica (Stengers, 2007), que buscará tomar o nixi pae como uma tecnologia de conectividade. Assim, espera-se desdobrar a semântica de termos como cura e medicina por meio da pragmática dos coletivos (de pajés, substâncias, espíritos) em ação: que efeitos estes geram quando agem em rede, o que movimentam, o que fortalecem, o que é deixado para trás. O nixi pae aparecerá então como peça-chave na ativação de coletivos ontologicamente heterogêneos, abrindo possibilidades para encontros com a alteridade em tentativas de composição de espaços de coexistência.

Palavras-chave: ayahuasca; cura; cosmopolítica; conectividade.

\begin{abstract}
In this paper, I propose to describe some aspects of a recent movement around the socalled "medicines of the forest", mainly the nixi pae (ayahuasca) of the Huni Kuĩ (Kaxinawá). The proposal includes the monitoring of continuous flows between the "forest" and the "city" of the nixi pae, the so-called pajés and the emerging groups around them, evidencing ontological conflicts and connections. A significant contribution of this work may lie in feeding reflections in the ayahuasca research field from a cosmopolitical proposition (Stengers, 2007), which will seek to take nixi pae as a technology of connectivity. Thus, it is hoped to unfold the semantics of terms like cure and medicine through the pragmatics of collectives (of shamans, substances, spirits) in action: what effects do these generate when they act in network, what moves, what strengthens, what is left behind. The nixi pae will then appear as a key element in the activation of ontologically heterogeneous collectives, opening possibilities for encounters with otherness in attempts of composing spaces of coexistence.
\end{abstract}

Keywords: ayahuasca; healing; cosmopolitics; connectivity. 
Canta, canta, Uirapuru

Com seu raio de amor

Na floresta tem ciência

Quem diga e nunca imaginou...

(trecho de canção de Tuim Nova Era).

O objetivo deste $\operatorname{artigo}^{1}$ é descrever alguns movimentos das chamadas medicinas da floresta entre os Huni Kuĩ (Kaxinawá), mapeando rastros e transformações que se dão entre ambientes de "floresta" e "cidade". No caso deste povo, as medicinas mais destacadas são o nixi pae (ayahuasca), o rapé (dume deshke), o kambô (kampũ), a sananga, entre outras que serão mencionadas mais adiante. Aqui apresento uma descrição inicial deste objeto de pesquisa, colada ao solo etnográfico, a fim de evitar sobrevoos teóricos em direção ao tema das diplomacias cosmopolíticas, que é onde pretendo chegar. No entanto, friso que este é o olhar e a perspectiva teórica - em consonância com a teoria ator-rede (Latour, 1994) - que guia o trabalho etnográfico. A ideia, assim, não é discutir filosoficamente termos como ontologia ou cosmologia, mas exaltar encontros e diferenças de perspectiva entre diversos actantes em campo.

O termo cosmopolítica é entendido aqui, sumariamente, como um olhar e uma abordagem. Uma abordagem que, por um lado, busca não negligenciar os não humanos, não colocando o humano no centro do universo, e que busca mapear complexas redes de ações (seguindo a ideia do faz-fazer de Latour), levando em conta a existência de um pluralismo ontológico; por outro, busca atentar para a dimensão política das ações, investigando relações de poder numa dimensão capilar (ou micropolítica) e a feitura de alianças e rupturas, descrevendo a que estão associadas. Como colocam Sztutman e Marras (2013), evocando autores como Latour, Goldman e Viveiros de Castro:

Como expressão a um só tempo de uma nova natureza da política e de uma nova política da natureza, o conceito/proposta de "cosmopolítica" ambiciona explorar

1 O material deste trabalho é composto por observações etnográficas feitas entre 2012 e 2016, bem como por entrevistas gravadas em 2016 com participantes de rituais huni kuĩ. Neste texto selecionei três entrevistas com nawá (não indígenas), pois exploro mais adequadamente as falas dos Huni Kuĩ em outros textos. 
relações simetricamente comparáveis entre coletivos muito distintos entre si, mas só aparentemente inconciliáveis no plano da análise. Dentre esses impasses privilegiaremos o que estamos chamando aqui de "contextos cosmopolitas", isto é, situações de sobreposição, convivência ou embate entre práticas e discursos "ocidentais-modernos" e "indígenas". Com isso, buscaremos fortalecer a aposta na comparabilidade de "modos de existência" ou "ontologias" (termos que, ao lado do dualismo "nós/eles", deverão ser problematizados), bem como no diálogo entre uma antropologia da ciência e uma etnologia indígena, algo que já tem sido experimentado pela assim chamada "Antropologia Simétrica".

Ressalto que esta é uma investigação um tanto perigosa, pois trata do uso de substâncias como o nixi pae, que, nesse contexto, estão imersas em assuntos, como a pajelança, que exigem uma série de conhecimentos e cuidados em campo para que seja possível construir uma abordagem por dentro dos acontecimentos ${ }^{2}$ (e não de fora, mas por meio de perspectivas que se transmutam, ora de dentro, ora de lado, ora mais afastada, ora assumindo a de outros actantes), buscando compreender diferentes ontologias e conexões que são efetuadas.

\section{As medicinas e seus movimentos}

Apesar de haver práticas (não suficientemente documentadas) do uso daquilo que genericamente se designa como ayahuasca ${ }^{3}$ entre populações "mestiças" e ribeirinhas na região fronteiriça entre Brasil, Peru e Bolívia mesmo antes do século XX, numa linha mais próxima ao que hoje se entende por "vegetalismo", um evento importante no início do movimento brasileiro em torno dessa bebida deve-se à história de Raimundo Irineu Serra, o Mestre Irineu, como é conhecido entre os adeptos do Santo Daime e demais linhas ayahuasqueiras, no início do século XX, na decadência do primeiro ciclo da borracha.

2 Nesse sentido, considero fundamental o uso, pelo pesquisador, das substâncias aqui mencionadas, nesse contexto específico (huni kuĩ).

3 Chá preparado a partir do cipó Banisteriopis caapi (conhecido como jagube, mariri ou, em hãtxa kuĩ, huni ou nixi pae) e da folha Psychotria viridis (conhecida como chacrona, rainha ou, em hãtxa kuĩ, kawa), fervidos com água. 
O encontro do Mestre com a Virgem, após a ingestão da Ayahuasca, seria o Mito Fundador da religião (Goulart 1996). Conforme indica Groisman, Irineu teria transformado "[...] simbolicamente a Ayahuasca em Daime, de certa forma domesticando, convertendo e sacralizando a bebida" (1999, p. 101). (Fernandes, no prelo).

À história de Mestre Irineu pode ser atribuído um marco no trânsito da ayahuasca (nomeada então santo-daime ou simplesmente daime por seus adeptos) do contexto indígena para comunidades ribeirinhas no Acre, assim como o estabelecimento de um ritual com formato e linguagem cristã com a mesma bebida $^{4}$ (Goulart, 2002). No entanto, não há registros de que nesse contexto se usava o termo medicina da floresta - apesar do uso disseminado de ervas e "remédios do mato" para o tratamento de doenças e problemas de saúde entre essas populações. Sendo assim, essa fase não é o foco deste trabalho.

O ponto aqui é descrever o que chamo de um movimento recente das medicinas da floresta, com a saída dos próprios indígenas acreanos e de suas medicinas em direção a centros urbanos no Brasil e em outros países, no início deste século, com a finalidade primária (ou secundária) de condução de rituais. Esse movimento tem um marco com a saída dos primeiros Huni Kuĩ ${ }^{5}$ em direção a cidades do sul do país. ${ }^{6}$

4 Há quem diga, como alguns indígenas, que não se trata da mesma bebida. Sem contar as diferenças de preparo, isto se dá principalmente por conta da mudança de nomes entre as etnias, por exemplo: uni, ayahuasca, nixi pae, huni pae, uni pae, kamarãbi, kamalambi, caapi, yagé, etc.

5 Os Huni Kuĩ são um povo falante da língua hãtxa kuĩ, pertencente à família linguística pano, e habitam territórios no Brasil e no Peru. No Brasil, na região acreana, os Huni Kuĩ vivem atualmente em 12 Terras Indígenas distribuídas nos rios Purus, Envira, Murú, Humaitá, Tarauacá, Jordão e Breu, com população estimada em aproximadamente 7,9 mil indivíduos (segundo os próprios Huni Kuĩ, a população hoje é de mais de 12 mil), constituindo $45 \%$ do total da população indígena do estado (Iglesias, 2014, p. 20). Do total, 67\% vivem em dez terras no vale do rio Tarauacá, afluente do rio Juruá. Há também um considerável número de famílias que vivem hoje nas cidades de Santa Rosa, Tarauacá, Jordão, Feijó e na capital Rio Branco. Em território peruano, pouco mais de 2,1 mil Huni Kuĩ (censos oficiais de 2007) vivem em 11 "comunidades nativas", oficialmente reconhecidas no alto rio Purus e no rio Curanja (Iglesias, 2014, p. 20).

6 Há sujeitos yawanawá e de demais povos saindo em outros momentos (Labate; Coutinho, 2014). No entanto, o meu foco aqui será exclusivamente nos Huni Kuĩ. 
Um desses casos é o de Fabiano Txana Bane, que partiu para o Rio de Janeiro em 2005 e lá fixou residência por quase uma década (Coutinho, 2011), como conta uma frequentadora ${ }^{7}$ de seus rituais:

O Fabiano chegou na cidade, assim, com uma missão de abrir a ayahuasca para as pessoas da cidade. Isso há 11 anos atrás. Onze anos atrás ninguém sabia o que que era índio, ninguém sabia o que que era ayahuasca. Quando sabiam o que era ayahuasca, ligavam ao Santo Daime e não à cultura huni kuĩ. E ele foi fazendo esse trabalho durante 11 anos. [...] E essa força que tem me vindo de firmar esse ponto. [...] Acho que é esse mesmo desejo que ouvi que falaram do Fabiano, que mais pessoas precisam tomar ayahuasca, mais pessoas precisam conhecer esse chá e que mais pessoas na cidade precisam saber quem são os Huni Kuĩ. Porque ainda é muito pouco, das pessoas que sabem. (Carou).

Desde então, diversas cidades do sul-sudeste ${ }^{8}$ do país têm recebido alguns Huni Kuĩ advindos de Terras Indígenas como dos rios Jordão, Humaitá e Envira (além de integrantes de outros povos, como Yawanawá, Shawãdawa, Katukina, Ashaninka, Shipibo-Conibo, etc.). Esse movimento tem crescido a cada ano e hoje já há uma rota de circulação por países como Inglaterra, Espanha, Itália, França, Holanda, Bélgica, Alemanha, Dinamarca, Noruega, Eslovênia, Letônia, Lituânia, Rússia, Israel, Índia e África do Sul.

O termo medicinas da floresta, ${ }^{9}$ no caso dos Huni Kuĩ, engloba o nixi pae e outras substâncias ${ }^{10}$ usadas em seus rituais contemporâneos: o rapé, o kampũ e a sananga.

7 Carou Trebitsch, 34 anos, é uma frequentadora e organizadora dos rituais indígenas de ayahuasca no Rio de Janeiro, integrante do grupo Guardiões Huni Kuin. Esta entrevista foi realizada em julho de 2016 durante o evento Living Gaia, em Alto Paraíso (GO), que contou com a participação de duas mulheres huni kuĩ do Jordão.

8 Nos estados de São Paulo, Rio de Janeiro, Minas Gerais, Paraná, Santa Catarina e Rio Grande do Sul.

9 Se formos buscar uma aproximação em hãtxa kuĩ para "medicina da floresta", encontramos algum paralelo com o termo dau, que designa tanto remédio como veneno.

10 O antropólogo Miguel Aparício propõe pensar o conceito de substâncias psicoativas em simetria com o que ele chama de humanos fitoativos - o que considero mais interessante, já que podemos transmutar a perspectiva padrão de causa-efeito, atentando-nos, assim, para o que as plantas fazem com os humanos. 
O rapé (dume deshke) é uma medicina para ser usada nas vias nasais. É um pó em geral feito de tabaco e cinzas de cascas de árvores, tais como cumaru (kumã), murici (yapa), pau-pereira, canela-de-velho (xiwe mapu), cacau (txashu desha), ouricuri (tashkã) e mulateiro. Essas cinzas são também chamadas de medicinas, pois não se prepara o rapé com cinzas de qualquer árvore, mas com aquelas que têm certas propriedades. $\mathrm{O}$ rapé pode ser usado individualmente por meio de um curipe (ou kuxipa), ou assoprado por uma pessoa em outra, com um tepi. Deve-se aplicar nas duas narinas, uma por vez. Quando uma pessoa recebe um sopro (ou ela mesma se aplica), ela deve suspender por um momento a inspiração nasal, mantendo a respiração pela boca. Da mesma forma, não se deve engolir o resíduo do rapé, mas cuspi-lo após algum tempo.

Para os Huni Kuĩ, há diferentes tipos de sopro: os mais comuns são o sopro da jiboia, longo e suave, usado para cura; o sopro do beija-flor, mais ligeiro (para despertar o corpo); o sopro do veado, forte, rápido e curto; o sopro do gavião, ainda mais prolongado. Em outra forma de classificação, há o que chamam de sopro caminho do sonho, para a pessoa dormir tranquila e ter bons sonhos, e, ainda, um sopro para limpeza, mais forte, próprio para a pessoa vomitar, chorar e/ou defecar.

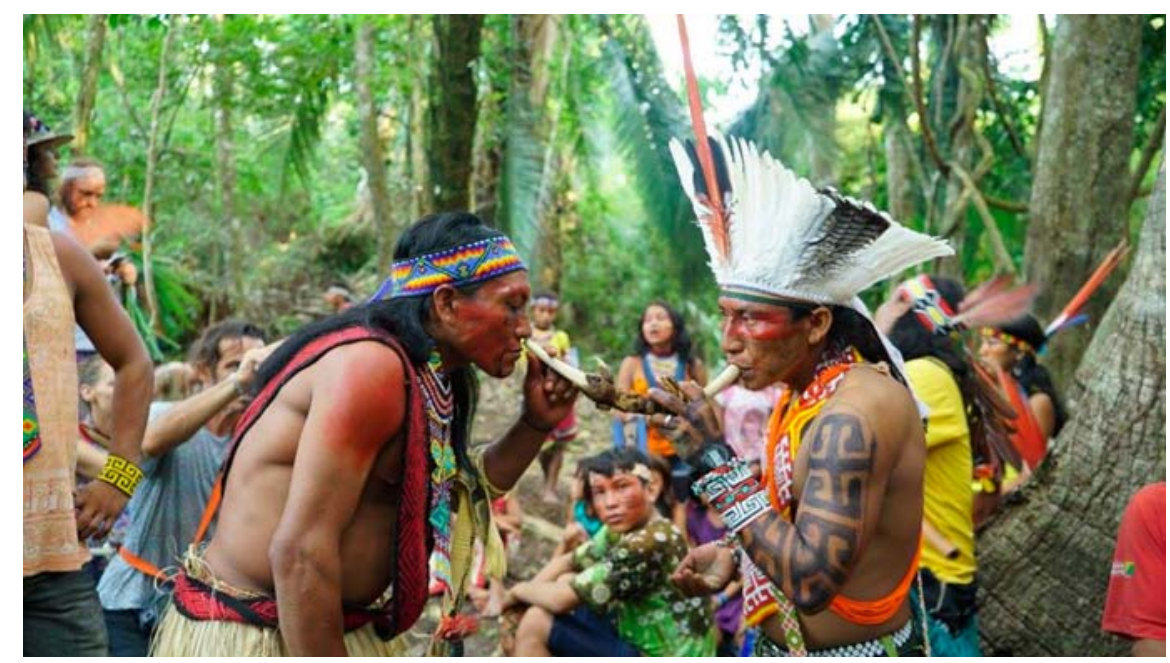

Figura 1. Aplicação de rapé (foto: Lisa Leiding, 2016). 
Segundo os Huni Kuĩ, o rapé pode ser usado para tirar enrasco (nisũ), limpar maus pensamentos, defender dos maus espíritos (por isto também é considerado uma "arma") e revigorar o corpo após um dia extenuante de trabalho no roçado (nesse caso é usado nos fins de tarde, ao pôr-do-sol). Outras pessoas também recomendam o uso logo pela manhã, ainda em jejum. Também há o uso durante rituais com nixi pae, onde a "força" pode ser intensificada pela combinação das duas medicinas. Além do uso para curar doenças ou problemas específicos, como combater o início de uma gripe ou limpar um nariz congestionado, o rapé, segundo alguns nawá (não indígenas), também pode ser usado para meditação. Entre os Huni Kuĩ, o rapé é usado estritamente como "medicina" (pertencendo ao rol de conhecimentos e substâncias de suas pajelanças); este, portanto, não deve ser misturado com álcool ou outras substâncias do mundo nawá (como o cigarro e demais "drogas").

Já a sananga (Tabernaemontana sananho) é uma medicina feita do sumo da casca de uma raiz e é aplicada nos dois olhos, como um colírio. Uma das diferenças em relação aos colírios dos brancos é que esta arde e provoca lágrimas. $\mathrm{O}$ ardor pode variar muito, dependendo do "grau" da medicina. A sananga deve ser usada preferencialmente fresca e seu recipiente guardado num local também fresco para que não estrague. Para os Huni Kuĩ, além de curar nisũ (panema), maus pensamentos e dor de cabeça, a sananga pode proporcionar curas de problemas oculares por meio de tratamentos com uma série de aplicações. Durante o efeito dessa medicina, a pessoa que está aplicando pode fazer rezas e massagens na região da testa da pessoa que recebe. Nos trabalhos huni kuĩ, a sananga é mais usada na parte final dos rituais, um pouco antes do fechamento.

O kambô (ou kampũ, em hãtxa kuĩ) é uma medicina aplicada na pele, que age diretamente na corrente sanguínea, como uma "vacina". Ela é a secreção de uma rã (Phyllomedusa bicolor), a qual é colhida da pele deste anfíbio e guardada, geralmente, em uma palheta (exceto quando se captura a rã e logo se faz a aplicação). De praxe, a pessoa que irá aplicar ${ }^{11}$ faz leves queimaduras com um palito grosso sem ponta na pessoa que irá receber, a fim de abrir

11 Segundo Lima e Labate (2007), para os Katukina, a pessoa que está aplicando está também passando os seus conhecimentos para a pessoa que irá receber. Há, pois, uma circulação de saberes e qualidades (como as virtudes do bom caçador) do aplicador para o receptor. 
os locais por onde irá entrar a secreção. No caso da aplicação nos nawá, o mais comum é se fazer de três a cinco pontos, variando também conforme o sexo e a idade (as crianças, e, em seguida, as mulheres costumam tomar menos que os homens adultos). Esse número pode ser bem maior (cf. Lima, 2005, no caso dos Katukina), ainda que os não indígenas dificilmente recebam mais de dez pontos. Nos homens, as queimaduras devem ser feitas preferencialmente na parte superior de um dos braços. Nas mulheres, perto do tornozelo.

Feitos os pontos, usa-se água para "soltar" a medicina da palheta, e, com a ajuda de um instrumento (faca ou pinça), deposita-se a secreção da rã em cima de cada ponto. A quantidade de pontos e a qualidade da secreção darão o tom da intensidade da experiência. Durante a aplicação, em geral, não há cantos e as pessoas devem ficar em silêncio. A pessoa que recebeu a medicina permanece então em seu local, em silêncio e concentrada, esperando a "força" chegar, o que geralmente acontece rápido. $\mathrm{O}$ efeito mais intenso se dá por 10 a 20 minutos, não sendo possível precisar com exatidão. Se a pessoa não conseguir suportá-lo, pode-se remover a medicina lavando com água o local da aplicação. Se estiver perto de um rio ou igarapé, também é possível entrar na água para esvair o efeito.

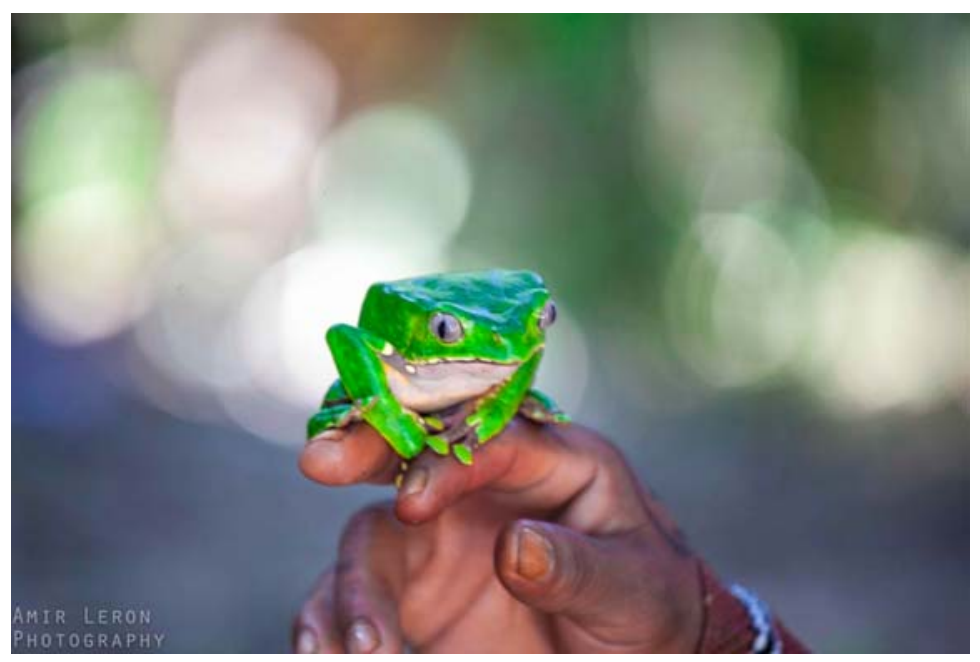

Figura 2. Kampũ (foto: Amir Leron, 2015). 
Para os Huni Kuĩ, o kampũ é uma medicina para "limpeza" (não propicia visões, como o nixi pae), isto é, que tem a finalidade de expelir do corpo da pessoa aquilo que está causando algum mal, assim como fortalecer sua imunidade contra doenças. Muitos afirmam que esta medicina somente tem o efeito desejado quando a pessoa vomita ou faz algum tipo de "limpeza". O objetivo, portanto, não é segurar, mas limpar. É comum, ainda, que algumas pessoas que recebam o kampũ "virem sapo", ou seja, que fiquem com o rosto e os beiços inchados, lembrando a aparência do próprio kampũ.

Depois da aplicação deve-se seguir uma dieta, que em geral envolve a abstinência sexual, de carne, doces (isto inclui a maioria das frutas, como banana e mamão), cebola, alho e sal. Os alimentos mais indicados para a dieta são legumes insossos, como a macaxeira e o milho. A duração da dieta varia conforme a intenção da pessoa, mas em geral devem-se observar as restrições com maior vigor de um a três dias. Além disso, não se deve comer em excesso, tampouco ficar parado ou deitado à toa - lembremos que o kampũ também é usado para tirar preguiça (tikish). Os Huni Kuĩ falam que se a pessoa não seguir a dieta, ela "perde o kampũ", isto é, o efeito prolongado (de imunização, limpeza) proporcionado pela medicina.

Como é possível verificar em trabalhos específicos sobre essa medicina (Lima, 2005; Lima; Labate, 2007), o kampũ era antigamente usado pelos homens para ter boa sorte na caça (tirar nisũ) e aguçar os sentidos para encontrar os animais. Nas aldeias, é aplicado logo cedo pela manhã, ao nascer do sol e fora da área de moradia, mais para dentro da mata. Nos rituais urbanos, a aplicação geralmente é feita depois de uma sessão de nixi pae, também por volta dessa hora.

Além dessas medicinas, também podem estar presentes em seus rituais o tabaco e a Cannabis, além de plantas usadas para defumação, as quais não serão exploradas aqui. Assim, a despeito das substâncias mais usadas em seus rituais, para os Huni Kuĩ as medicinas são primeiramente "espécies" (as quais, numa tradução breve, quer dizer basicamente "plantas"). O termo medicina abrange, portanto, plantas usadas para defumação, para banhos, para ingestão, para esfregar na pele, para cheirar, para aplicar nos olhos ou nos ouvidos, entre outros modos de uso, com propósito de tratar doenças específicas, mal-estar ou, como dizem os Huni Kuĩ, tirar nisũ. Segundo a antropóloga Aline Ferreira Oliveira (2016, p. 3-4): 
Precisamos pontuar algumas poucas questões sobre o termo medicina, pois assim vem sendo chamada uma ampla gama de plantas, animais e derivados, que estão chegando às cidades e sendo adentradas a diversos círculos ao redor do mundo, e são de prática e uso tradicional de populações nativas, seja de alguma das Américas ou África. "Medicinas da floresta", pois, é a forma como passaram a ser designadas a ayahuasca e outros agentes - tais como o rapé, o kambô, a sananga, etc. - relacionados à floresta: à Amazônia, seus povos, seus seres, seus cosmos e interações. Neste cenário, destaca-se a presença de indígenas do tronco linguístico Pano, habitantes de distintos rios no Acre, principalmente os Huni Kuin (Kaxinawa), [...] Yawanawa [...] e os Katukina.

Há profundos conhecimentos envolvidos no uso e na história de cada uma dessas medicinas, sendo possível redigir um trabalho específico em torno de cada uma delas (em minha tese, trabalho mais detidamente com o nixi pae). Há inclusive relatos de quando cada uma começou a ser usada e como se formaram os movimentos atuais em cada local, já que há algumas décadas o uso de muitas delas era restrito a poucas pessoas (geralmente "velhos"), que detinham seu conhecimento. A expansão do uso das medicinas da floresta, que se deu primeiramente dentro das aldeias, é um fenômeno de fato recente para o qual não há como determinar um início, como afirma Saulo Fernandes (no prelo, p. 8, grifo do autor):

[..] as Medicinas (rapés, Sananga, Kambô) chegaram ao Daime através da interação cultural entre povos indígenas do Acre - em especial os do tronco linguístico Pano e Aruak - com os daimistas da região. Não foi possível determinar em que momento e a partir de quais atores sociais as Medicinas passaram a ser usadas no circuito do Santo Daime, todavia creio que este foi um processo que aconteceu rizomaticamente, sem direção única, e que precisar um início seria inviável.

Fora as plantas, hoje há um uso expandido do termo medicina que abarca, por exemplo, a água, o ar, o canto de um pássaro, uma tenda do suor, uma fogueira, o Sol ou a Lua. Todos estes podem vir a ser medicinas (devir-medicina). Com a circulação entre "floresta" e "cidade", os modos de uso das medicinas têm sido profundamente transformados. Assim, endosso o argumento de trabalhos contemporâneos deste campo de estudos (Labate; Cavnar, 2014) que questionam 
o chavão de um uso "ancestral" (desde sempre, da mesma forma), presente no discurso de muitos usuários.

Hoje há distintas formas de usar cada uma das medicinas, sem seguir as mesmas dietas, horários e recomendações, criando novos formatos, em múltiplos ambientes (terapêutico, apresentações culturais e em rituais também distintos) e finalidades (como o tratamento de dependência de drogas, no caso do kampũ e da própria ayahuasca). Tendo isso em vista, sabe-se que há distintas ontologias e seres que compõem os seus múltiplos modos de existência, já que essas medicinas não existem e nem são usadas de forma solitária. Com esse breve mosaico, passemos agora a destrinchar outros conceitos-chave nesta discussão.

\section{Cura: múltiplos sentidos e traduções}

Se estamos falando de medicinas (ou remédios), estamos necessariamente falando de cura. Esse termo, assim, também deve ser colocado em suspensão. Aqui novamente há uma multiplicidade de sentidos e contextos, como atenta Ferreira Oliveira (2016, p. 4):

[...] assim como o termo medicina, há uma variedade de traduções entre termos outros - como cura, floresta e espiritualidade - abrindo um campo amplo de possibilidades e diálogos. Isto porque seus variados campos semânticos são consoantes em alguns pontos, e podem assim confluir também para entendimentos mútuos, porém operando por tradução, por serem distintos.

Na cosmologia huni kuĩ, a origem das doenças está relacionada ao sangue dos animais (portanto, ao consumo de carne). Segundo Agostinho Ĩkamuru, citado por Haibara (2016, p. 122), as doenças originaram-se a partir da mistura dos diferentes sangues, feita durante os processos de constituição dos bebês, filhos dos Huni Kuĩ com as pessoas que surgiram por meio da transformação do sangue das caças. Assim, cada tipo de doença surgida em tal contexto está relacionado ao consumo de determinados tipos de caça, sendo que são os yuxĩ (espíritos, almas) daqueles bichos que vêm vingar-se, especialmente durante os sonhos (Lagrou, 1998, p. 56), em que podem aproveitar o momento 
de dispersão dos yuxĩ da pessoa, adentrando em seus corpos e gerando as

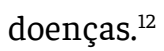

Para os Huni Kuĩ (e em certa medida, também para os nawá citados adiante), não há uma separação entre o que seja uma doença física, mental, emocional ou espiritual. Entende-se que os corpos (visíveis e invisíveis) estão conectados e não divididos. A ideia de cura, assim, não está restrita às fronteiras implícitas no conceito de indivíduo, como comenta Carou, frequentadora ${ }^{13}$ dos rituais huni kuĩ, em entrevista:

A medicina a gente toma para se curar. Uma coisa que eu gosto muito que eu aprendi com a medicina é que cada um toma para se curar de uma forma particular, mas eu sinto que por onde a força huni kuĩ passa, essa cura do individualismo, ela tem sido transformada. Para trabalhar com os txais assim não tem como estar sozinho. Não tem como ser uma pessoa e chegar lá e fazer um projeto sem ter muita gente por trás. E quando você começa a tomar o chá, você percebe essa cura do individualismo, que tem muito na nossa sociedade, transformando. Aí você começa a entender que na floresta eles são bem coletivos, né, comunidade. Eu acho que essa é uma cura para mim, para o meu entendimento.

Isso permite pensar cura não só de uma pessoa, mas de uma coletividade (e até do próprio planeta, como costumam dizer os Huni Kuĩ durante as sessões de nixi pae com os nawá), já que o desequilíbrio de uma pessoa não seria somente dela, mas de uma coletividade e, em última instância, de todos. Qual seria,

12 Segundo Yano (2010, p. 85), boa parte da etnografia kaxinawá ressalta que "a doença tem origem externa à pessoa: instilam-lhe veneno (dau), seduzem-lhe a 'alma' ( $y u x i)$, adentram em seu corpo substâncias que a impedem de ouvir, enxergar, se comunicar (Lagrou, 1991; McCallum, 1996; Deshayes, 1992; Keifenheim, 2002). Nas entrelinhas, portanto, '[...] entende-se que um agente externo rompeu o equilíbrio entre o corpo e seus espíritos [...]' (Lima, 2000, p. 58) - pois, se um corpo ativo e saudável é aquele que tem os yuxĩ juntos a si, como define Lagrou (2007, p. 309), a doença configura, em contraposição, nada mais que a ameaça de dispersão desses yuxĩ."

13 Nos interessa aqui explorar o pensamento desses não indígenas de modo a multiplicar as formas de entendimento dessa questão, da qual são actantes fundamentais e trazem elementos que somam ao debate. Esquecê-los, numa tentativa de produzir um trabalho puramente "etnológico", seria contradizer a própria proposta cosmopolítica e a investida latouriana rumo à constituição de um "parlamento das coisas". Os nawá (e aqui me incluo) participam dessas redes, criam alianças, fazem-fazer uma série de coisas. Sem eles, pois, tais movimentos não se efetivam. 
então, a origem desta "doença social"? Abaixo, Romina Lindemann, ${ }_{14}^{14}$ outra frequentadora dos rituais huni kuĩ, expõe seu entendimento:

Eu vejo que a nossa sociedade ela está doente. [...] indícios que eu vejo, por exemplo, são os prédios. E os vizinhos, que normalmente você nem conhece. E aí evita encontrar no elevador porque você não quer dar nem bom dia. Isso para mim é uma coisa muito estranha. Tem uma fala de uma índia [...], ela nunca tinha visto prédio, e ela disse assim: "Devem gostar muito um do outro, moram tão pertinho..." E é justamente o contrário que acontece, as pessoas mal se falam. [...] Às vezes a pessoa está ali passando um sofrimento muito grande do seu lado e não tem para quem correr, às vezes se joga de uma janela. E depois você sofre. E aquele momento que você sabe que às vezes que precisava dar um olhar de bom dia, uma presença real, era só talvez aquilo que ela precisava. E você não conseguia porque você estava ocupado, pensando em outra coisa, ou já no seu lar, atento ao que você tinha que fazer e não olhou para aquele ser que estava mais próximo de você e precisava de uma atenção. Então eu vejo alguns indícios de uma sociedade doente e que a medicina traz clareza. $\mathrm{E}$ a partir dessa clareza você pode fazer alguma coisa, porque está muito inconsciente. Eu sinto, por exemplo, a televisão como um outro causador desse não olhar para dentro. Porque você está toda hora olhando para fora na televisão, vendo as coisas de fora, e não permitindo criar um espaço para olhar para dentro. [...] E a medicina ela vem e ela fala, "cara, se você não vai olhar...", e te mostra de qualquer jeito. Porque você não tem para onde correr. Que é aquela coisa, você pode esconder de todo mundo e não pode esconder de Deus. É quase isso com a medicina, eu sinto, porque afinal o nixi pae é yuxibu, ${ }^{15}$ é Deus, é tudo.

14 Romina Lindemann, 37 anos, também pertence ao grupo Guardiões Huni Kuin, no Rio de Janeiro, onde trabalha com projetos e organização de rituais de ayahuasca. Romina se diz empreendedora social. É Diretora Comercial/Marketing na empresa Preserva MUNDI e Diretora de Projetos na Floresta Viva em Mim. A entrevista com ela foi feita em Novembro de 2016 na cidade de Tarauacá, antes de embarcarmos para a T.I Kaxinawá do Rio Humaitá, onde se deu o III Festival Huni Kuin Eskawatã Kawayai.

15 Numa tradução possível, yuxibu seria algo como grandes espíritos ou donos. Estão ligados ao que os Kaxinawá chamam de "forças da natureza", como o vento (niwe), o Sol (bari), a Lua (ushe), as estrelas (bixi) a floresta (ni), a samaúma (shunu), etc. 
Com esta fala, recuperamos o argumento do sociólogo Georg Simmel, para o qual o individualismo está estritamente ligado ao modo de vida do ser humano nas grandes cidades. Em seu clássico As grandes cidades e a vida do espírito (de 1903), o autor escreve que "o fundamento psicológico sobre o qual se eleva o tipo das individualidades da cidade grande é a intensificação da vida nervosa, que resulta da mudança rápida e ininterrupta de impressões interiores e exteriores" (Simmel, 2005, p. 577-578, grifo meu). Essa intensificação pode ser associada à "aceleração" característica da vida nas cidades.

Na mão contrária, movimentos nos quais participam as medicinas da floresta estão mais afinados com movimentos de desaceleração: estes lançam um olhar generoso, assim, à vida na aldeia, ao interior, aos conhecimentos dos índios e das populações "tradicionais". É inegável, por outro lado, que a chegada do nixi pae nas cidades grandes transforma seus cidadãos e as próprias cidades. Mas estas também afetam, por outro lado, as medicinas e os índios, quando estes passam a frequentá-las.

Na visão desses frequentadores de rituais, as cidades e as pessoas que nelas vivem precisariam da "cura da floresta" porque estariam (previamente) doentes. Carou adiciona um ponto novo na discussão: os índios, por sua vez, precisariam da "cura das cidades". Esse termo, assim, adquire uma multiplicidade de sentidos:

O que tem vindo para mim muito na força é de firmar essa corrente nas grandes cidades. Porque essas grandes cidades precisam dessa cura dos txais e eles precisam dessa cura das cidades. E como, assim, é uma coisa que eu gosto muito, que me motiva a estar na cidade trabalhando com os txais, que eles falam que eles entenderam que eles precisam se unir com a gente para continuar nessa força, para não acabar. É muita demanda que tem. É muita coisa que eles precisam de recurso. $\mathrm{E}$ as cidades têm esses recursos. Em compensação a cidade, por ter muito esse recurso, as pessoas estão doentes. Então eu vejo que a presença dos txais na cidade é tão importante quanto a nossa presença na floresta [...]. Eu sinto que tem um espaço aí. (Carou).

Nessa colocação parece que cura tem a ver com a cunhagem de trocas entre o que um tem e o que o outro não tem: o índio levando uma coisa para o branco (não necessariamente material, como o conhecimento das medicinas 
da floresta) e o branco oferecendo em troca alguma coisa para o índio (idem, como o conhecimento das tecnologias digitais ou de certos recursos que têm em abundância).

Com isso, pode-se entender que um dos propósitos principais dos nawá envolvidos com os trabalhos com as medicinas huni kuĩ é colaborar com a construção de uma ponte entre a "cidade" e a "floresta", como eles próprios afirmam:

O que eu sinto que é a nossa missão principal é essa ponte entre a cidade e a floresta. [...] Não é à toa que eu tenho tatuado kapa hena, que é o rabo do jacaré. E eu pessoalmente, na minha vida pessoal, no meu trabalho, eu já sou muito isso, né, de fazer essa conexão entre os mundos e entre as pessoas. (Romina).

Essa fala nos permite começar a pensar o nixi pae enquanto um "agente conector de mundos", ou, como proporei mais adiante, uma tecnologia de conectividade. No entanto, é preciso antes dar um passo atrás: afinal, o que seriam essas duas categorias: "floresta" e "cidade"? Considerando novamente a multiplicidade de sentidos e agenciamentos envolvidos, esses termos não devem ser tomados como autoevidentes. Será que cidades como Jordão (AC), Tarauacá (AC), Rio Branco (AC), São Paulo (SP) e Londres (Inglaterra), para dar um exemplo de um trajeto percorrido por alguns Huni Kuĩ, têm as mesmas características? São cidades da mesma maneira? Simetricamente, é pertinente o argumento que tampouco a maioria dos Huni Kuĩ vive no meio da floresta, mas em aldeias dentro de Terras Indígenas e nas próprias cidades fronteiriças. O que seria, então, floresta?

Por enquanto, o que sabemos é que esses dois termos são aqui pensados em oposição. Essas categorias precisariam, portanto, ser devidamente colocadas em suspensão para desdobrarmos suas múltiplas facetas a partir da prática etnográfica (o que não faremos aqui suficientemente por restrição de espaço). O que se pode adiantar é que, por mais que "floresta" e "cidade" possam remeter a lugares concretos, elas atuariam nos discursos como aproximações da realidade.

Uma aproximação simplificadora e generalista, no entanto, não é o que nos interessa aqui, já que procuramos justamente complexidade, a heterogeneidade e a multiplicidade, mapeando associações a partir de diferentes 
perspectivas e as colocando em relação, com o intuito de "abrir", mais do que "fechar", as possibilidades de entendimento.

Neste momento considero oportuno recuperar o conceito de circuito, ${ }^{16}$ elaborado pelo antropólogo José Guilherme Magnani (2014, p. 8), que o define como "a configuração espacial, não contígua, produzida pelos trajetos de atores sociais no exercício de alguma de suas práticas, em dado período de tempo". O conceito de circuito nos ajuda a não cair na cilada de tomar a "cidade enquanto uma totalidade dada, discreta, com papel explicativo ou definidor de comportamentos, práticas, situações - a violência, o individualismo, a segregação etc. - perspectiva tão a gosto da mídia e arraigada no senso comum" (Magnani, 2014, p. 9), e, da mesma forma, a "floresta" como o local da "comunidade" e da "Natureza". Pensar, assim, em circuitos e trajetos pode nos ajudar a descrever movimentos em torno das medicinas indígenas por diferentes cidades, vilas, aldeias, rios e florestas - que podem ser mapeados a partir das trajetórias de diferentes actantes, como, por exemplo, os frequentadores de rituais urbanos e as próprias medicinas.

Nessa toada, recuperamos o relato de Romina, no qual ela afirma que há basicamente dois momentos na trajetória usual de um adepto das medicinas indígenas: o primeiro, no qual a pessoa participa de um ritual com os índios nas cidades (geralmente em seu país ou local de residência), e o segundo, quando a pessoa vai para "a floresta". Esse é o trajeto mais comum que uma pessoa percorre para chegar, por exemplo, nos festivais - existindo, claro, exceções, como pessoas que aguardam para tomar ayahuasca pela primeira vez "na floresta" ou que conheceram os Huni Kuĩ já em suas aldeias, tendo visto apenas um flyer na internet ou contando com a indicação de algum amigo ou parente.

São dois momentos, eu sinto. A gente faz um primeiro movimento com os que estão interessados em conhecer [...]. Mas tem pessoas que já estão estudando há um tempo, já estão buscando informação, que sentem o chamado e, na hora certa, chega, né, porque tudo é perfeito. $\mathrm{E}$ a importância que eu sinto

16 Segundo Magnani (2014, p. 9), "o circuito não é dado de antemão, mas construído: são os trajetos dos atores sociais que criam, mobilizam e o tornam vivo, assim como é o observador que circunscreve, põe em contato e articula determinadas dimensões desse circuito no curso de sua etnografia". 
é isso, de aproximar esses dois mundos, que eles coexistem, mas muitas pessoas acham que ele não existe [...]. Então eu sinto a importância desse resgate, dessa reconexão, consigo mesmo e com a floresta. E aí num primeiro momento acontece nas cidades, as pessoas vão começando a se dar conta até que chega esse outro caminho. E eu sinto, já tinham me dito isso antes e eu comprovei, que a sua vida é uma antes e outra depois da medicina, não tem como mudar; e num segundo momento, é uma antes e outra depois da floresta, não tem como mudar, porque as transformações acontecem, o seu encontro com a verdade ele é tão profundo, que não tem como você não estar andando nessa linha. (Romina, grifo meu).

Como é visível nesse discurso, há, geralmente, por parte dos interessados nesses rituais, uma busca por uma ancestralidade e por um modo de uso "original" das medicinas por povos que as utilizam "há tempos indeterminados", que "guardam" esse conhecimento. A despeito de que hoje existam diferentes tipos de rituais com as medicinas - desde aqueles praticados por linhas consideradas tradicionais do Santo Daime e de demais segmentos cristãos àquelas com influências da umbanda, até do movimento Nova Era - há, no caso desses viajantes, uma busca por uma autenticidade indígena. Pois, como alguns falam, essa medicina "é dos índios", ou, pelo menos, "veio dos índios".

Romina coloca que um de seus papéis nesse movimento é ajudar a promover uma aproximação entre dois mundos (nawá e huni kuĩ), que passam então a coexistir. Ela, assim como os demais interlocutores citados neste texto (e mesmo eu próprio), aparecem, como mediadores entre esses diferentes "mundos" e ontologias, abrindo canais e operando traduções. Poderíamos nos perguntar, com interesse na discussão sobre esses movimentos, afinal, o que circula nessa tal ponte?

Em princípio, possivelmente qualquer coisa: desde pessoas, conhecimentos, remédios, artesanatos, dinheiro, amor, gratidão, cura, inveja, magia, feitiços, computadores, pensamentos, projetos, cantorias, pinturas, mulheres, homens, crianças, animais, terra, água, poços artesianos, placas solares, medicinas, xampu, banheiros secos, gasolina, barcos, hospedarias, penas, tambores, bananas, etc. Com tanta mistura, que direção dar a esse turbilhão? Afinal, por que esses canais foram e continuam a ser abertos pelos actantes envolvidos nessa trama? 
Chegamos, assim, à reflexão acerca das motivações e dos propósitos que envolvem a circulação das medicinas da floresta e seus pajés: um ponto fundamental na discussão. Observamos, pois, que uma das motivações pelos actantes em campo tem um caráter eminentemente profético: em seus trabalhos espirituais, os pajés estariam "levando a cura da floresta para a cidade" por meio das medicinas. Essa seria sua missão primordial, que aparece em seus discursos oficiais. O índio aparece então como mediador cosmopolítico (Stengers, 2007), que leva a cura para o "mundo do branco" (ou "a sociedade"), como nesta fala de Ninawá Pai-da-Mata: ${ }^{17}$

Os novos pajeres [sic] são pessoas que estão transformando os conhecimentos nesse novo tempo. Transformar o conhecimento não é perder a tradição, é buscar novas formas de lidar a com a sociedade. [...] Nesses últimos anos, o trabalho da pajelança através dos jovens indígenas tem avançado muito dentro do Estado brasileiro. A cura da floresta chegando para a sociedade através desses novos sábios. Para mim, esses trabalhos são muito importantes hoje mostrar essa realidade para o mundo. [...]. Olho como trabalho de muita importância trazer a cura da floresta através das medicinas.

No entanto, considerando a polissemia de cada um desses termos (cura, cidade, floresta), é possível vislumbrar outros objetivos não necessariamente declarados, como a formação de alianças com o Outro, como lembra Carou:

Eu vejo que o maior propósito é a união com pessoas diferentes. Esse encontro mesmo. Eu acho que não é pelo dinheiro que eles fazem isso. Eu não vejo que o propósito inicial seja uma pessoa fazendo isso. Embora a gente saiba que uma coisa é propósito e outra coisa é o que a vida mostra. A gente já vê pajés que não pensam na comunidade e que pensam só neles. Mas no geral, acho que propósito é que eles saiam para o mundo para ajudar os Huni Kuĩ como um todo. A valorização dessa cultura.

17 Francisco Mateus, conhecido como Ninawá Pai-da-Mata, mora na aldeia Novo Futuro na TI Kaxinawá do Rio Humaitá. Ele conta que em 2000 recebeu da comunidade a confiança de trabalhar como líder espiritual de sua aldeia e que, desde então, é um líder que faz articulação política, social e cultural dentro e fora da Terra Indígena. 
Para elucidar a questão, segue abaixo a letra de um cântico bastante presente nos rituais huni kuĩ com instrumentos. Este apresenta a figura do "caboclo curador", que remete às viagens dos pajés pelo mundo:

Chegou, chegou o caboclo curador

Ele roda o mundo inteiro, pra aliviar a nossa dor

Esse caboclo é caboclo verdadeiro

Ele atira as suas flechas muito mais além do mar

Esse caboclo é caboclo da Jurema

Com seu cocar de pena faz o mundo balançar

Chegou, chegou o caboclo curador

Ele roda o mundo inteiro pra aliviar a nossa dor

Ele nos traz a cura da floresta

Seu canto é de amor, que vem do coração

Yube mana ibubu, mana ibubu butã

Eskawatã kawayei, kawayai kiki

Nessa letra, pode-se inferir que o caboclo (ou índio) tem a capacidade de "trazer" a cura da floresta por onde andar. Mesmo sem estar na floresta (ou em sua aldeia), ele pode carregar essa força consigo. Algumas pessoas comentam que certos Huni Kuĩ que já não vivem na floresta há certo tempo (os quais fixaram residência em cidades) perdem um tanto dessa força em relação àqueles que estão sempre retornando. Entretanto, outras falam que os índios (e isso não se aplica somente aos pajés, mas aos demais "representantes") irão trazer essa força independentemente de estarem morando ou não na "floresta", mas se estão verdadeiramente conectados com as medicinas:

Tem txais que estão na cidade há muitos anos. E tipo, Ailton Krenak, que está na cidade há muito tempo, o próprio Fabiano... Você vê que a floresta continua neles. Que eles conseguem ter um equilíbrio muito bom com a cidade, mas que eles estão sempre naquela presença da floresta. Não importa se eles vêm só fazer um ritual ou se eles vêm para ficar mais, para passar uma vida. [...] Se ele está 
conectado ali com a medicina, eu sinto que ele está conectado com a floresta mesmo. Esses são os exemplos que eu vejo que o txai quando vem para a cidade ele não vira branco, ele carrega muito da floresta com ele. (Carou).

Como se pode interpretar na letra do cântico do "caboclo curador", a missão (num sentido religioso ou "espiritual") desses pajés é percorrer o mundo todo, trazendo cura. A chave aqui está em notar que esta intenção não é somente humana, mas também das próprias plantas e espíritos, como afirma Mariana Maia, ${ }^{18}$ outra frequentadora dos rituais:

[...] o mundo está precisando da medicina, está precisando dessas curas, e eu sinto também que é muito a ver com a própria vontade mesmo da medicina, do espírito da floresta, yuxibu, de chegar onde está precisando chegar. E aí usando os veículos, as diferentes maneiras de conseguir essa expansão. [...] que o mundo está precisando mais do que nunca mesmo.

As medicinas da floresta são muitas vezes entendidas pelos nawá como aquelas que vêm curar os "males da civilização", que está hoje em crise generalizada. Esse entendimento encontra forte conexão com a cosmologia Nova Era, a qual geralmente veicula uma imagem do indígena como um ser "sábio" e "puro". Nessa visão, aqui na cidade (também chamada "selva de pedra" por seus adeptos), estaríamos precisando dessa luz trazida pelos indígenas, que seriam mensageiros espirituais de uma tradição ancestral que propiciaria uma conexão mais verdadeira com a natureza, curando o planeta dos "males do desenvolvimento".

Leila Amaral (1998, p. 100 apud Labate, 2000, p. 224) postula que "o termo Nova Era estaria ligado, assim, a uma ideia de cura como transformação radical [...] a transformação da consciência, primeiro no plano interno-individual". Amaral afirma que se trata, enfim, da restauração da saúde da Terra,

18 Mariana Maia, 34 anos, é fardada na igreja Céu do Mar no Rio de Janeiro e participante do grupo Guardiões Huni Kuin na mesma cidade. Mariana é produtora cultural e presta assistência à Cooperativa Huni Kuin Aru Kuxipá. Hoje também leva grupos de viagens às aldeias e acompanha lideranças espirituais huni kuĩ e yawanawá em suas viagens. A entrevista com Mariana foi feita durante o III Festival Huni Kuin Eskawatã Kawayai, na aldeia Novo Futuro, TI Kaxinawá do Rio Humaitá. 
concebendo-a como a "grande reconciliação". A antropóloga Beatriz Labate (2000, p. 225) coloca que "nesta busca de transformação radical, cura e salvação tonam-se sinônimos".

Esta obsessão pela cura está ligada a um discurso de catástrofe iminente, sobre o final dos tempos; ou de transformação astrológica, da passagem da era de peixes para a era de aquário; ou, ainda, de transformação de paradigma, do materialismo para o holismo. A cura do indivíduo está ligada ao restabelecimento de uma ordem planetária e cósmica (Amaral, 1998 apud Labate, 2000, p. 224, grifo da autora).

Está implícito nesse referencial da cosmologia Nova Era certo evolucionismo às avessas: quando mais primitivo, melhor. No entanto, todos, índios e não índios, agora despertos pelas medicinas, estaríamos na missão de salvar a floresta e o planeta das "forças do mal", do capitalismo, da destruição do próprio planeta ou algo semelhante. Nessa busca por definição, encontramos uma conexão com esta citação de Isabelle Stengers (2015, p. 25-26), onde ela tenta precisar o que seria o capitalismo:

Em contraste com Gaia, ele [o capitalismo] deveria é ser associado com um poder de tipo "espiritual" (maléfico), um poder que captura, segmenta e redefine a seu serviço dimensões cada vez mais numerosas do que constitui nossa realidade, nossas vidas e nossas práticas. [...] Lutar contra Gaia não tem sentido, trata-se de aprender a compor com ela. Compor com o capitalismo não tem sentido, trata-se de lutar contra seu domínio.

Para aprofundar a discussão, entraremos em aspectos envolvendo escatologias ou visões de fim do mundo, onde o nixi pae e demais medicinas atuariam, nesse contexto de crise, para curar o mal não só do indivíduo, mas da civilização.

\section{O nixi pae e a intrusão de Gaia}

O diagnóstico atual de crise não é comum apenas entre os acadêmicos, mas também entre atores do campo. Mariana cita a teoria de Gaia (Lovelock, 2006) para elucidar seu entendimento acerca desses movimentos com as medicinas: 
Da maneira como eu vejo, como eu tenho sentido, é que a própria Terra, assim... Aquela teoria de Gaia, a Terra tentando se curar através da medicina que ela tem, tentando se curar de uma coisa que quase que virou uma doença para a Terra... Eu lembro que, nessa época da minha adolescência também que eu parei de tomar [daime], eu tive um período muito triste, meio deprimida, sentindo que eu fazia parte do câncer da Terra [...] E depois eu melhorei, mas eu ainda sinto que isso tem uma verdade nessa maneira como a gente está vivendo na Terra, cada vez mais (ou talvez cada vez menos, eu espero, né); mas como acelerou mesmo esse desequilíbrio. E da maneira como eu vejo, é muito a própria Terra buscando se curar ou curar os seus filhos através da medicina. E eu acho que é uma vontade maior mesmo do espírito da floresta, do espírito da Terra, do espírito da medicina, de chegar aonde está precisando chegar. E fazer essas curas, fazer essa limpeza, despertando na consciência, acordando as pessoas. E está acontecendo. [...] A gente passou lá também na Inglaterra, e uma galera, assim, com muita grana, milionária, eles falaram que "estão trocando os diamantes por penas". Em um ano a vida deles mudou radicalmente. $\mathrm{E}$ isso está acontecendo em vários lugares. Pessoas com histórias às vezes pesadas. Então acho que nesse momento planetário, a Terra está precisando mais que nunca, as pessoas estão precisando mais do que nunca. E aí a própria Mãe Natureza está encontrando maneiras e usando pessoas como veículos. A gente às vezes quando ajuda nos trabalhos, a gente está só servindo a essa causa maior, que não é eu nem você. Que nem os Huni Kuĩ falam: "Não é eu, nem você, nem o pajé, nem ninguém que está fazendo a cura, é a medicina." E a gente é um instrumento.

Pensar-nos como instrumentos e as medicinas (e a própria Terra) como agentes é uma aproximação afinada com a filosofia de Latour e a teoria ator-rede. A partir dessa percepção, refletir sobre a crise atual, pois, é pensar também em soluções contemporâneas. Tendo isso em vista é que as parcerias nawá-huni kuĩ se efetivam. Romina, por exemplo, conta que os índios desconhecem uma série de procedimentos em relação ao que hoje se chama de "manejo sustentável". Fica evidente que os Huni Kuĩ, permacultores e demais agentes de movimentos ambientalistas operam em lógicas distintas, apesar de haver pontos de encontro que possibilitam alianças pragmáticas.

O nível de inserção e degradação que o homem está fazendo nas mineradoras, de madeireira principalmente, petróleo, de tudo, e vários pontos da Amazônia, 
é muito preocupante. Você vê diretamente o impacto na água [...]. E os próprios txais, assim, pela ignorância de realmente não saber os impactos que eles causam, caso de queimada na beira do rio, mata ciliar, essas coisas... Eles mesmos fazem uma coisa contra eles mesmos. Então eu vejo que a gente tem um papel muito dessa ponte, de trocar essa ideia mesmo. De trazer o que que está dando certo em outros lugares para eles prestarem atenção, eles observarem e eles mesmos testarem. (Romina).

Há exemplos de tentativas bem-sucedidas ou fracassadas de parcerias. Isso depende, em alguma medida, da forma como os múltiplos atores, com suas diferenças ontológicas e pragmáticas, conseguem se conectar. Romina pontua adiante uma série de transformações em curso neste novo tempo (xinã bena), apontando a importância vital das medicinas nos movimentos de reflorescimento da cultura dos povos indígenas acreanos (que ela chama de "resgate"):

Eles têm os exemplos dos antigos, muita coisa eles perderam, muitas coisas manteram [sic], muita coisa eles estão usando de seringueiro. Então tem um mix hoje da cultura, já não tem uma coisa original, né, e já mudou muito o que que era originalmente. Tudo bem, o que que é isso? Faz parte do fluxo da mudança a gente aceitar. Mas como que a gente trabalha para melhorar? [...] Eu vejo que se o povo huni kuĩ, através do uso do nixi pae, da medicina sagrada, eles conseguiram e estão conseguindo fazer esse resgate de cultura. Que a medicina ela tem um papel fundamental hoje, que antigamente dizem que só era usado pelos pajés para fazer algumas consultas esporádicas; hoje faz parte você manter a cultura viva. Que poderia ter sido completamente degradada pela escravidão, pelo álcool, pela entrada [...] do português [língua] também [...]. Então é um movimento da medicina muito importante nesse momento.

O que ela chama de mix da cultura, ao invés de ser entendido pelas teorias do contato interétnico, pode ser lido aqui, via Roy Wagner (2010), por processos de invenção e convenção. "Resgate", apesar de também ser um termo usado entre os próprios indígenas, é, sem dúvidas, um termo problemático para descrever o movimento atual em torno da cultura huni kuĩ, a qual é recheada de novos usos e criações. Não há uma simples retomada do "antigo" ou de um "ancestral" 
sem modificações. A própria interlocutora atenta que a cultura é dinâmica, assim como Carou, colocando em discussão, via campo, conceitos clássicos da disciplina antropológica:

Falar de cultura é complicado. Porque a cultura ela se transforma. Então você não tem como falar da cultura ali muito paralisada. [...] A natureza se transforma também. [...] A cultura está em transformação o tempo todo, assim como a natureza. E aí eu posso dar um exemplo sobre cultura e natureza e pessoas de fora, que é o problema da água com os Huni Kuĩ. A água, ela está onde a natureza tinha naquele rio limpo, que eles podiam beber. Hoje em dia, com óleos e xampus e mil coisas, eles já não podem beber essa água. E aí como que eles conseguiram melhorar isso? Através desse encontro com a cidade. E a cultura deles também está sendo transformada, porque com uma água boa as mulheres não precisam ir até o rio pegar água. Provavelmente daqui a pouco vai ter a torneira, e já vai mudar essa cultura.

A cidade aparece, assim, como o local da origem de malefícios (daí viriam o xampu, óleos e "mil coisas") e, paradoxalmente, a solução dos problemas. Dentro disso, a degradação do meio ambiente (atribuída aos nawá) implicaria uma transformação do modo de vida dos índios - transformação esta que envolve, em muitos casos, a adoção de práticas e costumes antes a eles estranhos. Seria isso uma forma de colonização sorrateira ou uma saída possível, já que a destruição seria iminente?

De todo modo, devemos atentar para as ontologias e conceitos presentes nas falas. O termo natureza não está sendo colocado por essa interlocutora num sentido lévi-straussiano (em oposição a Cultura), tanto porque esta não excluiria os humanos, tampouco seria estagnada ou "externa", mas dinâmica, inclusiva e imanente; operante no mesmo nível das relações:

[...] os índios, quando eles mostram esse contato com a natureza, eles também mostram que a natureza não está abaixo da gente. Que é uma coisa que a Igreja Católica e muita gente veio cortando isso da gente, onde a gente acha que a gente é mais do que a natureza. E os índios vêm mostrar para a gente justamente ao contrário. Então isso também é uma cura, que é quando a gente começa a olhar para uma árvore de um jeito diferente. [...] eu acho que para eles [os Huni Kuĩ], 
eles não têm muito acima [...]. A gente acha que a gente está acima da natureza. Para eles, eles são a natureza. Que é a verdade, né. Nós somos a natureza. E a natureza está na terra. Não está no céu. Não está naquele Jesus Cristo, branco, de barba branca. [...] E yuxibu mesmo, né, yuxibu para eles é tudo. É o que eles tão vendo. Eles são yuxibu, uma árvore é yuxibu, o mar é yuxibu. É tudo aquilo. Eu nunca ouvi falar que yuxibu é alguém externo. É sempre essa conexão com a terra mesmo, com o que tem aqui. (Carou).

Nessas falas há uma oposição marcada entre a "linha da floresta" e as religiões cristãs, ${ }^{19}$ aproximando a primeira, assim, das cosmologias ameríndias. Essas diferenças ontológicas, pois, têm efeitos práticos, que se manifestam no nível da conduta de seus seguidores. No entanto, entre alguns povos indígenas, segmentos espirituais e mesmo religiões, como o cristianismo, a busca da cura (ou do preparo) para a destruição da Terra (ou fim dos tempos) se dá no aqui-e-agora.

Com o fim do mundo iminente (de certo modo, ele está acontecendo todos os dias!), basta-nos cortar a rede, notando perigos que corremos.

\section{Perigos à vista?}

É inegável que nesses encontros entre índios e brancos (mediados pelas medicinas) invariavelmente estão presentes conflitos ontológicos, bem como aquilo que Viveiros de Castro (2004) chamou de práticas de comunicação por equívoco. Há situações que adentram em casos limítrofes entre ontologias indígenas e não indígenas.

Perigo tem muito, principalmente com ayahuasca. Teve um caso agora, que dois índios jovens foram pra Europa, levaram a bebida sagrada deles, e quando chegaram lá, eles foram deportados. Porque eles estavam levando droga. Ainda não

19 Cujos segmentos ayahuasqueiros, como o Santo Daime, em outras circunstâncias, apareceriam como aliadas, já que costumam estabelecer parcerias em muitos rituais de medicina e situações afins, com a cessão do espaço de suas igrejas para abrigar os trabalhos indígenas, caracteristicamente nômades. 
tem esse entendimento. E esse perigo, ele existe. Eles foram presos. E imagina para um índio sair lá da aldeia, onde aquela bebida é a coisa mais sagrada, e ele chega num outro país que é droga. Então, o perigo com o álcool, com as prostitutas, que é uma coisa que já está entrando na floresta também. Que são as coisas ruins desse encontro. Mas também não tem como a gente achar que só vai ser luz. (Carou).

Acerca desses encontros, uma das regularidades que podemos apontar é a presença marcante da ideia de empoderamento no discurso dos nawá que trabalham de perto com os Huni Kuĩ. A participação dos não indígenas nesse processo de circulação dos Huni Kuĩ e das medicinas entre "floresta" e "cidade", ou mesmo na expansão do uso do nixi pae, se daria no sentido de uma tutela atual visando uma autonomia futura (outro conceito complicado). No entanto, nesse caminho não se estaria livre de perigos e incertezas:

[...] perigo sempre existe. [...] Por enquanto a gente está lidando um outro problema, de uma outra geração, que era o paternalismo. Essa coisa que o branco sempre dava para os índios. Agora o que eu vejo é que nesse momento é que a gente está agenciando eles, em diversos setores, para que no futuro eles possam ser eles mesmos agenciados. E se eles vão encontrar com uma pessoa muito legal [...], ou se eles vão encontrar com uma pessoa mau-caráter, que quer pegar mais do dinheiro da comissão do ritual para ele, em benefício dele e não para os índios. Existe esse perigo, mas também tem exemplos ótimos. (Carou).

O interesse no embate entre perspectivas ou ontologias não reside, pois, em saber se uma é verdadeira ou não, mas descrever diferentes agenciamentos e intenções, já que o problema da cosmopolítica elucidado por Stengers seria justamente como compor a partir da ideia de que existem vários mundos. Proponho, então, tomar o nixi pae e as demais medicinas da floresta como tecnologias de conectividade, isto é, como actantes que operam conexões entre diversos mundos, sem os quais não há comunicação possível.

O nixi pae, assim, aparece novamente como chave privilegiada para acessar esses mundos povoados de seres e entidades de ontologias heterogêneas, todos eles animados - agindo, pois, como um mediador de relações, um diplomata cosmopolítico que abre uma visão "cósmica”, alargada, em seus usuários. 
Essa medicina, o nixi pae, é o que os Huni Kuĩ têm de mais sagrado. Eles se encontram ali, eles decidem as coisas não só com o que eles pensam, mas com o espiritual. E é isso daí também é o que eles trazem para a cidade [...]. A gente percebe que acima da gente tem o espiritual todo. E também eu acho que isso daí pode ser a cura. Quando você toma o nixi pae, quando você vê os seres, quando você enxerga que em cima de você tem uma lua, e que a natureza está ali... A primeira vez que eu tomei nixi pae, a primeira resposta que me veio foi: "Olha pra natureza." E eu acho que olhando pra natureza, tomando seu rapé ali, sozinha, e se conectando mesmo com a Terra, com a Lua, com as estrelas, você sente que você não é nada, você é só uma poeira, quando você dá esse zoom out que a ayahuasca faz, você vê que você é muito pouco. [...] Que é isso que a ayahuasca mostra. Que o mesmo tempo que você é só um nada nessa Terra, você é tudo, porque a sua vida está em você. (Carou).

O perigo, no entanto, permanece. Com todos os agenciamentos que envolvem o nixi pae e as medicinas nos dias atuais, seriam estes, enfim, capturáveis pela feitiçaria capitalista de que falam Pignarre e Stengers (2005)? Estar alerta é de suma importância. No entanto, podemos mais tomar tais questões como controvérsias a explorar do que cair em meras acusações "externas". De uma forma ou de outra, estamos lidando com magia: seja a feitiçaria do capitalismo, sejam as feitiçarias e contrafeitiçarias dos pajés (inka nai bei), cantadores (txanas), erveiros (dauya) huni kuĩ e mesmo dos nawá iniciados nas medicinas. Pelo menos uma coisa é certa: alguns têm preparo para lidar com esses conhecimentos e estão ganhando terreno. As medicinas, simetricamente, têm sabedoria e estão espalhando suas raízes.

Ainda é apressado tirar maiores conclusões. De fato, há profundas transformações em curso. Pode-se afirmar, no entanto, que não é o homem, pretenso senhor do mundo numa visão modernista, quem guia solitariamente essas mudanças, mas, sobretudo, os yuxibu e as próprias medicinas, que, com seus ensinos e orientações, estariam agora indicando novas direções. Assim, é fundamental abrir ainda mais um entendimento cosmopolítico dessa trama, percebendo relações interespecíficas e mesmo invisíveis que perpassam o campo e que transformam e transformam-se incessantemente, deixando rastros impregnados no solo e nos corpos daqueles que são por elas afetados. 


\section{Referências}

COUTINHO, T. Xamanismo da floresta na cidade: um estudo de caso. 2011. Tese (Doutorado em Sociologia e Antropologia)-Instituto de Filosofia e Ciências Sociais, Universidade Federal do Rio de Janeiro, Rio de Janeiro, 2011.

FERNANDES, S. C. As Medicinas da Floresta: o consumo ritual de psicoativos no circuito do Santo Daime. In: LABATE, B.; GOULART, S. O uso de plantas psicoativas nas Américas. Campinas: Mercado de Letras. No prelo.

FERREIRA OLIVEIRA, A. Plantas, dietas, éticas yawanawa: iniciações xamânicas contemporâneas. In: REUNIÃO BRASILEIRA DE ANTROPOLOGIA, 30., 2016, João Pessoa. Anais... Brasília: ABA, 2016. Disponível em: <https://neip.info/novo/wp-content/uploads/2016/07/Oliveira_Plantas_dietas_\%C3\%A9ticas_YawanawaABA_Joao-Pessoa_2016.pdf>. Acesso em: 20 maio 2017.

GOULART, S. O contexto de surgimento do culto do Santo Daime: formação da comunidade e do calendário ritual. In: LABATE, B.; SENA ARAÚJO, W. (Org.). O uso ritual da ayahuasca. Campinas: Mercado de Letras; São Paulo: Fapesp, 2002. p. 277-302.

HAIBARA, A. Já me transformei: modos de circulação e transformação de pessoas e saberes entre os Huni Kuĩ (Kaxinawá). 2016. Dissertação (Mestrado em Antropologia Social)-Faculdade de Filosofia, Letras e Ciências Humanas, Universidade de São Paulo, São Paulo, 2016.

IGLESIAS, M. P. Trajetórias huni kuĩ. In: ĨKA MURU, A. M. M. K.; QUINET, A. Una Isĩ Kayawa: o livro da cura do povo huni kuĩ do rio Jordão. Rio de Janeiro: CNCFlora/ JBRJ: Dantes, 2014. p. 20-23.

LABATE, B. A reinvenção do uso da ayahuasca nos centros urbanos. 2000. Dissertação (Mestrado em Antropologia Social)-Instituto de Filosofia e Ciências Humanas, Universidade Estadual de Campinas, Campinas, 2000.

LABATE, B.; CAVNAR, C. Ayahuasca shamanism in the Amazon and beyond. New York: Oxford University Press, 2014.

LABATE, B.; COUTINHO, T. O meu avô deu a ayahuasca para o mestre Irineu: reflexões sobre a entrada dos índios no circuito urbano de consumo de ayahuasca no Brasil. Revista de Antropologia, São Paulo, v. 57, n. 2, p. 215-250, 2014.

LAGROU, E. Caminhos, duplos e corpos: uma abordagem perspectivista da identidade e alteridade entre os Kaxinawá. 1998. Tese (Doutorado em Antropologia Social)Faculdade de Filosofia, Letras e Ciências Humanas, Universidade de São Paulo, São Paulo, 1998.

LATOUR, B. Jamais fomos modernos. São Paulo: Editora 34, 1994. 
LIMA, E. C. de. Kampu, kampo, kambô: o uso do sapo-verde entre os Katukina. Revista do Patrimônio Histórico e Artístico Nacional, Rio de Janeiro, n. 32, p. 254-267, 2005.

LIMA, E. C. de; LABATE, B. "Remédio da ciência" e "remédio da alma": os usos da secreção do kambô (Phyllomedusa bicolor) nas cidades. Campos, Curitiba, v. 8, n. 1, p. 71-90, 2007.

LOVELOCK, J. Gaia: cura para um planeta doente. São Paulo: Cultrix, 2006.

MAGNANI, J. G. O circuito: proposta de delimitação da categoria. Ponto Urbe, São Paulo, n. 15, 2014.

PIGNARRE, P.; STENGERS, I. La sorcellerie capitaliste: pratiques de désenvoûtement. Paris: La Découverte, 2005.

SIMMEL, G. As grandes cidades e a vida do espírito. Mana, Rio de Janeiro, v. 11, n. 2 , p. 577-591, 2005.

STENGERS, I. La proposition cosmopolitique. In: LOLIVE, J.; SOUBEYRAN, O. (Ed.). L'émergence des cosmopolitiques. Paris: La Découverte, 2007. p. 45-68.

STENGERS, I. No tempo das catástrofes: resistir à barbárie que se aproxima. São Paulo: Cosac Naify, 2015.

SZTUTMAN, R.; MARRAS, S. Cosmopolíticas e cosmopolitismos: diálogos entre a Antropologia da Ciência e da Modernidade e a Etnologia Indígena. Ementa do curso. São Paulo: Universidade de São Paulo, 2013. Disponível em: <https://jyvukugi.wordpress.com/ementa-e-cronograma-do-curso-cosmopoliticas-e-cosmopolitismos-i-semestre-de-2013/>. Acesso em: 20 maio 2017.

VIVEIROS DE CASTRO, E. Perspectival anthropology and the method of controlled equivocation. Tipití, San Antonio, v. 2, n. 1, p. 3-22, 2004.

WAGNER, R. A invenção da cultura. São Paulo: Cosac Naify, 2010.

YANO, A. M. T. A fisiologia do pensar: corpo e saber entre os Caxinauá. 2010. Dissertação (Mestrado em Antropologia Social)-Faculdade de Filosofia, Letras e Ciências Humanas, Universidade de São Paulo, São Paulo, 2010.

Recebido: 26/05/2017 Aceito: 14/03/2018 | Received:5/26/2017 Accepted: 3/14/2018 